\title{
Seep-bubble characteristics and gas flow rates from a shallow-water, high- density seep field on the shelf-to-slope transition of the Hikurangi subduction margin
}

\author{
B. Higgs ${ }^{\mathrm{a}, \mathrm{b}, \mathrm{c}}$, J.J. Mountjoy ${ }^{\mathrm{b}, *}$, G.J. Crutchley ${ }^{\mathrm{c}, \mathrm{d}}$, J. Townend $^{\mathrm{a}}$, Y. Ladroit ${ }^{\mathrm{b}}$, J. Greinert ${ }^{\mathrm{d}, \mathrm{e}}$, \\ C. McGovern ${ }^{\mathrm{d}, \mathrm{e}}$ \\ ${ }^{a}$ School of Geography, Environment, and Earth Sciences, Victoria University of Wellington, Wellington, New Zealand \\ ${ }^{\mathrm{b}}$ National Institute of Water and Atmospheric Research, Wellington, New Zealand \\ ${ }^{c}$ GNS Science, Lower Hutt, New Zealand \\ ${ }^{\mathrm{d}}$ GEOMAR Helmholtz Centre For Ocean Research, Kiel, Germany \\ ${ }^{\text {e } C h r i s t i a n-A l b r e c h t s ~ U n i v e r s i t y, ~ I n s t i t u t e ~ o f ~ G e o s c i e n c e s, ~ K i e l, ~ G e r m a n y ~}$
}

\section{A R T I C L E I N F O}

Editor: Gert J. De Lange

Keywords:

Gas seeps

Acoustic flare

Hikurangi margin

Methane emissions

Measuring seep bubbles

\begin{abstract}
A B S T R A C T
We analyse an area of high density submarine methane gas seeps situated on the shelf to slope transition (130-420 m water depth) on the northern region of New Zealand's Hikurangi margin, off Poverty Bay. Multibeam and singlebeam echo sounder data collected in 2014 and 2015 revealed $>600$ seeps, at much greater density than any previously mapped areas of seepage on the Hikurangi margin. To broadly constrain the output of methane from these seeps, we have estimated the flow of methane at individual seeps, utilising perspectivemeasurements applied to still frames from a deep towed camera system to measure the dimensions of rising bubbles. We combine bubble size and rise-rate distributions with singlebeam acoustic data to estimate gas flow rates at six selected seeps sites. Our results predict a wide range $(3.0-2249 \mathrm{~mL} / \mathrm{min})$ of methane release into the water column. If we assume that the six seeps we analysed are representative of the entire seep population, and that gas flow is constant, we can extrapolate across the seep field and infer a gas release of 30 to $2415 \mathrm{t}$ of methane per year into the ocean.
\end{abstract}

\section{Introduction}

Submarine methane seepage is a widespread natural phenomenon occurring in many different areas of the world's seafloor (e.g. Clark et al., 2000; Judd et al., 1997; Naudts et al., 2006; Shakhova et al., 2014). The methane emitted from seeps may originate from relatively shallow microbial activity (Colwell et al., 2008) or deeper thermogenic sources (typically $>750 \mathrm{~m}$ below the seafloor (mbsf) (Ritger et al., 1987). Submarine seeps can either be characterized by bubble release (Greinert and Nützel, 2004) or the discharge of dissolved fluids (Mazzini et al., 2004) into the water column. Bubble release can be identified using sonar echosounders or underwater camera footage (Heeschen et al., 2003; Naudts et al., 2010), while seepage in general can be identified by high concentrations of methane in the water column, unique chemosynthetic communities on the seafloor, and precipitates of authigenic carbonates at and in the seafloor (Greinert et al., 2010).
As methane bubbles are transported upwards through the water column, the majority of the methane is dissolved in the water column (Guinasso and Schink, 1973), which makes it accessible for aerobic oxidation by bacteria (Valentine et al., 2001). In some cases, anomalously high atmospheric methane concentrations have even been recorded directly above submarine gas seeps (e.g. Römer et al., 2017). Pohlman et al. (2017) provide evidence that upwelling from oceanographic processes, independent of gas seepage, is likely responsible for methane from $\sim 90 \mathrm{~m}$ water depth being transported towards the sea surface. In general, the input of methane into the oceans has important implications for local marine biogeochemistry and biodiversity (Gibson et al., 2005; Sibuet and Olu, 1998; Torres et al., 2002).

In this study, we report on a previously unknown field of methane seeps on the upper slope and shelf of the northern Hikurangi margin, off the coast of Poverty Bay in northeastern New Zealand (Fig. 1). We have identified $>600$ individual gas seeps in an area of $90 \mathrm{~km}^{2}$, that we collectively refer to as the Tuaheni seep field. The seeps represent by far

\footnotetext{
* Corresponding author.

E-mail address: joshu.mountjoy@niwa.co.nz (J.J. Mountjoy).
} 


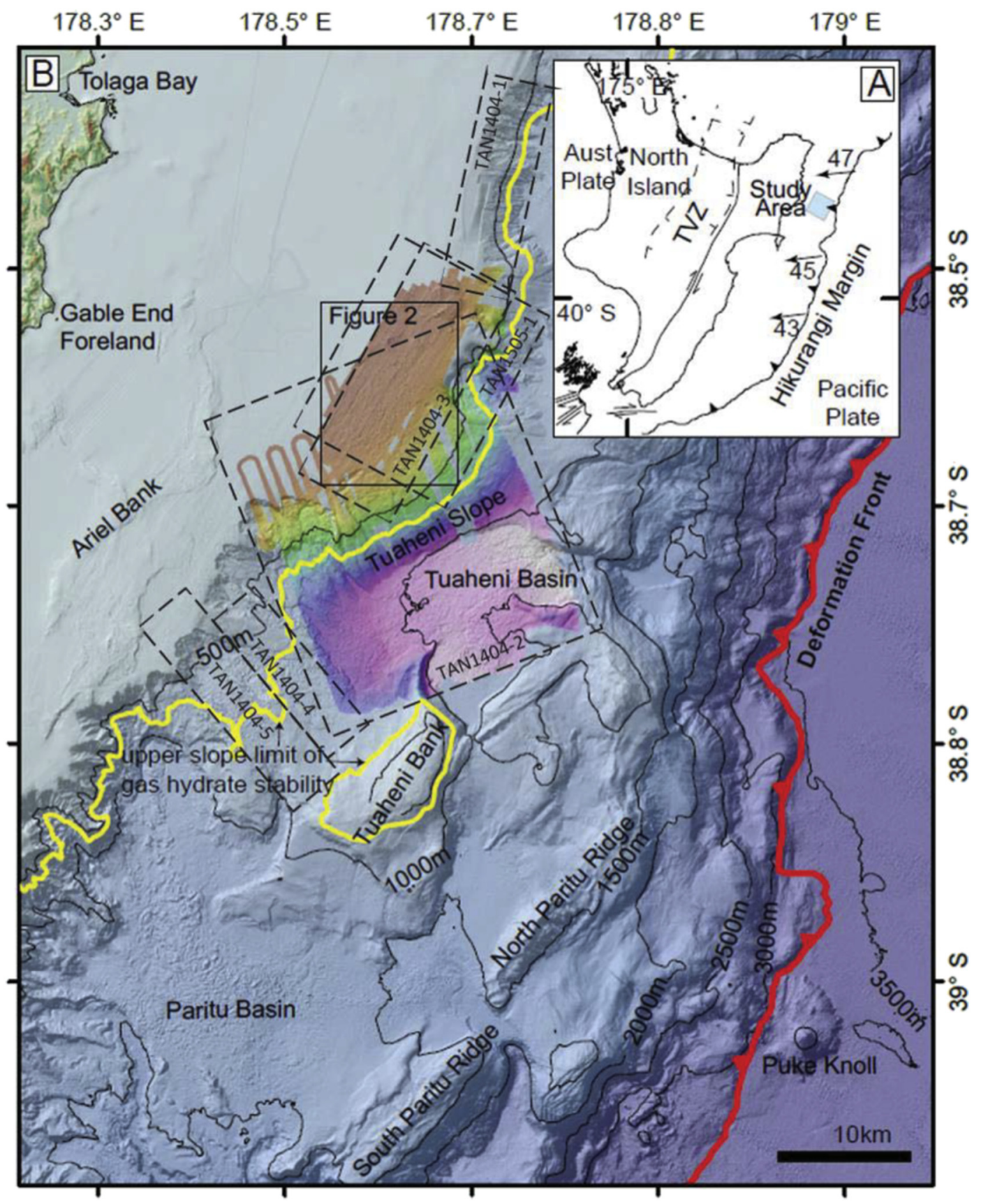

Fig. 1. Map displaying the surveyed bathymetry coverage of the research area. The yellow line shows the approximate upper limit of the gas hydrate stability zone. The red line shows the position of the deformation front at the Pacific-Australian plate boundary. The inset map shows the location of the study area with respect to the Hikurangi Margin. The multibeam surveyed area for the surveys TAN1404 and TAN1505 used in this study are divided into six areas, indicated by dashed boxes labelled TAN1404-1 to TAN1404-5 and TAN1505-1.(For interpretation of the references to colour in this figure legend, the reader is referred to the web version of this article.)

the densest distribution of methane seepage yet recognized in New Zealand's exclusive economic zone. To constrain the flow rate of methane from the seafloor, we use computational techniques for characterizing and quantifying bubble release. We determine statistical distributions of gas bubble sizes and rise rates using perspective measurement techniques applied to video imagery; we estimate gas flow rates by combining these results with the hydroacoustic backscatter of gas bubbles in the water column measured in singlebeam echo sounder data. We use these techniques to assess the gas flow rate of selected seeps in the Tuaheni seep field and then make estimations of total methane release into the water column.

\subsection{Geologic setting}

The Hikurangi Margin, New Zealand, (Fig. 1) has formed in response to the westward subduction of the bathymetrically elevated Hikurangi Plateau (Pacific Plate) beneath the overriding Australian Plate (Barnes et al., 2010). The Pacific Plate subducts beneath the Australian Plate at a rate of $40-50 \mathrm{~mm} / \mathrm{yr}$ (Barnes et al., 2010; Beavan et al., 2002; Davey et al., 1986). The margin exhibits significant alongstrike variation in tectonic style, as well as sediment thickness and geomorphology of the subducting plate, and has formed a highly variable accretionary wedge along the toe of the overriding Australian Plate as a result (Barnes et al., 2002; Collot et al., 1996; Field and 
Uruski, 1997; Lewis and Pettinga, 1993). The wedge consists of eroded Plio-Pleistocene trench sediments from the Hikurangi Trough, while the inner margin is a deforming backstop of late Cretaceous and Palaeogene passive margin sediments that predate subduction (Barnes et al., 2010).

Fluid generation and transportation in the subduction wedge is attributed to the dewatering of the lower subducting plateau (Lewis and Marshall, 1996). Fluids contained in saturated trench sediments entering the accretionary wedge are expelled from the Pacific Plate in response to the compressional stress regime (e.g. Davey et al., 1986). Of the order of $24 \mathrm{~m}^{3}$ of fluid per meter of strike length per year is expelled into the margin from the Pacific Plate (Townend, 1997). More than $80 \%$ of this has been attributed to compaction, with an additional $3 \mathrm{~m}^{3}$ per meter of strike length per annum released by smectite dehydration (Townend, 1997).

Clear spatial relationships between seeps and major seaward-vergent thrust faults on the middle continental slope suggests that transportation of fluids, including free gas, to the near-surface occurs via permeable thrust faults and fractures and that deep fluids are transported towards the outer (eastern) edge of the deforming Cretaceous and Paleogene foundation rocks (Barnes et al., 2010). Buoyant free gas is also able to migrate through the gas hydrate stability zone towards the seafloor, sometimes taking advantage of structural conduits formed by tectonic deformation, and sometimes by generating its own subvertical conduits (e.g. Barnes et al., 2010; Crutchley et al., 2010; Koch et al., 2015; Krabbenhöft et al., 2010; Netzeband et al., 2010). To date, published geochemical analyses of gases escaping at seep sites have indicated a biogenic source (Koch et al., 2016; Luo et al., 2016).

Our study site is at the northern end of the Hikurangi Margin in an area where repeated slow slip is occurring on the plate interface (Wallace et al., 2016). Slow slip behaviour has been linked to subducting seamounts and fluids (Bell et al., 2010). Gas hydrates occur throughout the northern Hikurangi Margin in water depths greater than $\sim 650 \mathrm{~m}$. Immediately downslope of our study area the gas hydrate system exhibits a double bottom simulating reflection (BSR). The double BSR is inferred to be a result of uplift and related to fluid pulses over the subducting seamount (Pecher et al., 2017). Prior to this current study, gas seepage was not identified in this area and so, as well as calculating methane flow rate for this high-density seepage site, our results provide the first evidence for widespread, focused seafloor fluid flow on the northern Hikurangi Margin.

\section{Data}

This study uses datasets collected by the RV Tangaroa during the TAN1404 survey in June 2014 and the TAN1505 survey in July 2015. Multibeam EM302 data collected during the TAN1404 survey first revealed the shallow Tuaheni seep field. The TAN1505 survey was then undertaken to target areas of interest across the seep field, which were surveyed acoustically using EM302 multibeam and EK60 singlebeam sonar systems. A subset of seeps was also imaged using towed video transects.

\subsection{Singlebeam data}

Split-beam data were acquired over the study area based on exiting multibeam coverage, using five frequencies of a Simrad EK60s echosounder $(18,38,70,120$ and $200 \mathrm{kHz})$, with a beam-width of $12^{\circ}$ for the $18 \mathrm{kHz}$ and $7^{\circ}$ for the other frequencies (Fig. 2). Data recorded for specific gas flares were extracted and saved using ESP3, an open-source software package for processing acoustic data sets (Ladroit et al., 2018). This package is conventionally used for fisheries research, so we made modifications to enable viewing and saving of acoustic flare profiles.

\subsection{Multibeam data}

Multibeam data were collected over seeps using a Kongsberg Simrad
EM302 multibeam echosounder (MBES), mounted on the hull of the vessel. The echosounder operates at a frequency of $30 \mathrm{kHz}$. We used a swath coverage sector of $55^{\circ}$, in equi angle mode with a pulse length of $5 \mathrm{~ms}$. The sampling rate was determined by a Kongsberg K-Synch unit so we could simultaneously operate the multibeam, sub-bottom profiler and ADCP without interference. The EM302 system applies beam focusing to both transmitted and received beams in order to obtain maximum resolution. Dynamic focusing was applied to all received beams. The transmitted beams are electronically stabilised for roll, pitch and yaw, while the received beams are stabilised for roll movements. Seafloor Information System (SIS) (Bikonis et al., 2006) was the real-time software application used on board for multibeam data acquisition. Bathymetric information from multibeam data was processed using Teledyne CARIS software and binned to $5 \mathrm{~m}$ grid size.

\subsection{DTIS footage}

Bubble release at seeps was video recorded using NIWA's deeptowed imaging system (DTIS). The DTIS was operated at $2 \mathrm{~m}$ above the seafloor for both video tows at 0.6 knots tow-speed as well as stationary video recordings (Fig. 2). A Canon 10 MP digital SLR camera with a $24 \mathrm{~mm}$ lens was used to capture still images every $15 \mathrm{~s}$; a Sony $1080 \mathrm{P}$ camcorder captured high-definition colour video. A pair of lasers attached $200 \mathrm{~mm}$ apart enable scaling of footage.

\section{Methods}

The sections below outline the methods we have used to estimate flow rates of methane from seeps in the Tuaheni seep field. We estimated these flow rates using the inverse hydroacoustic method described by Veloso et al. (2015), which incorporates a seep bubble size distribution (BSD), bubble rise-rate distribution (BRD), singlebeam acoustic flare profiles, as well as chemical and physical parameters as input factors. The total number of seeps was derived visually, by counting individual flare signatures in echograms of multibeam data.

\subsection{Bubble-dimension measurements}

To quantify gas release we used Canadian Grid-based perspective measurement techniques described by McGovern (2012) and applied them to DTIS footage of seep bubbles to measure their size and height above the seafloor. We automated these measurement techniques in Matlab codes (Mathworks, MA) that can be obtained from the Pangaea data publishing service (see Acknowledgements). As the method is not accessibly published, it is summarized in the supplemental materials (supplement S1). When applying these techniques to video-recorded seep bubbles, we assume the seafloor is a horizontal plane following the methods of McGovern (2012). The refractive indices of air and water were set to 1.000 and 1.334 respectively (Bashkatov and Genina, 2003).

\subsection{Bubble rise rate}

Our video data only allowed us to clearly observe rising bubbles at one location. We obtained velocity values for individual bubbles at seep site 1 (Figs. 2 and 4) by measuring the elevation of bubbles above the seafloor every five frames from the time the bubble emanated from the seafloor until it left the video frame. We ensured that the same bubble was tracked across the frame intervals by also recording and plotting the (equivalent) radius of the bubble. The rise rate of each bubble was calculated by dividing the determined bubble rise height by the elapsed time (frame rate multiplied by the number of frames).

\subsection{Uncertainties in video measurements}

The degree of uncertainty in the size and elevation of bubbles depends most significantly on the location of the bubble in relation to the 


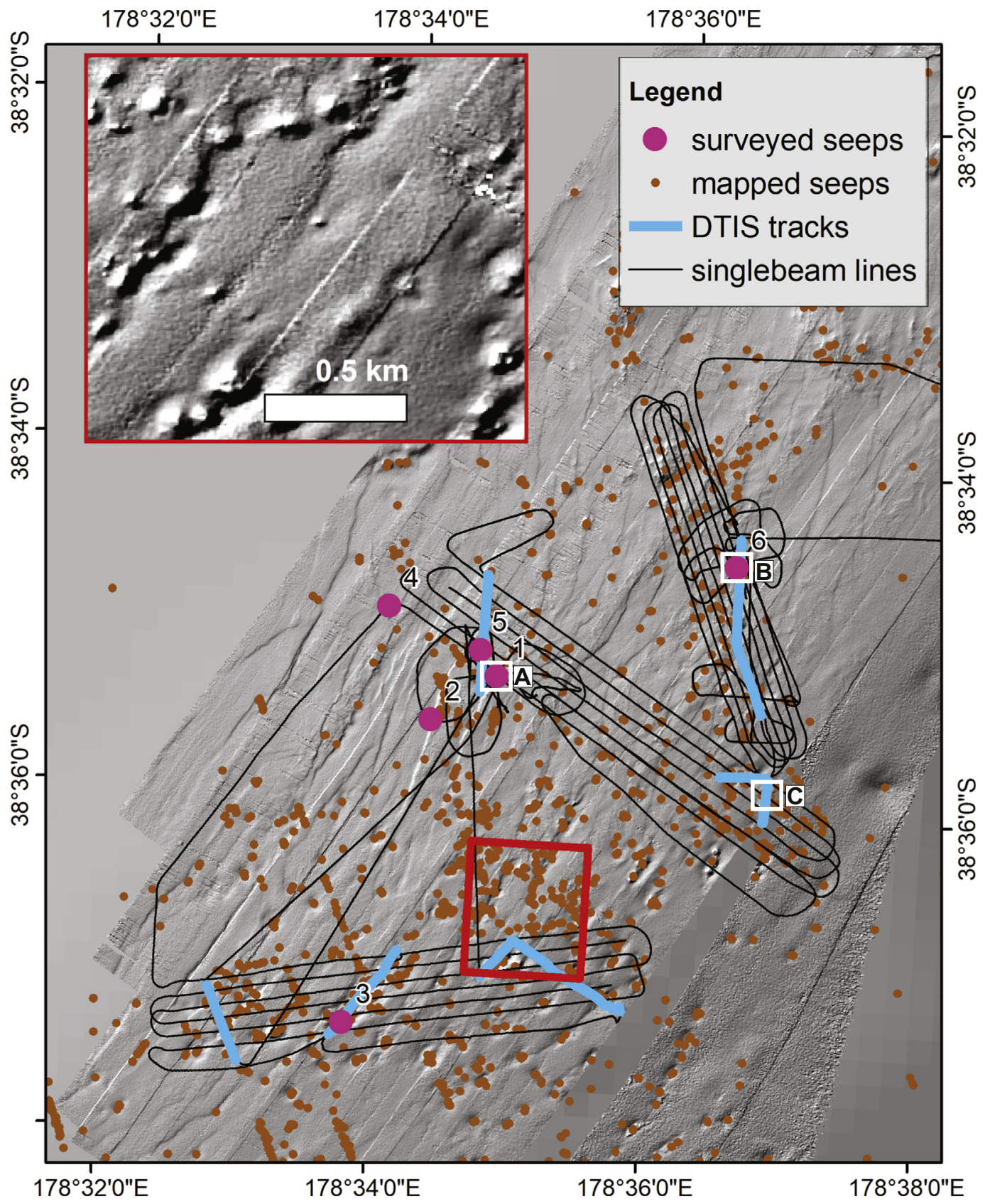

Fig. 2. Enlarged map from Fig. 1, displaying the distribution of data collected during TAN1404 and TAN1505. The navigation of collected singlebeam data and DTIS footage is shown as black lines and blue lines respectively. Grey hillshade underlying the figure indicates the distribution of $30 \mathrm{kHz}$ multibeam echosounder data. Brown dots indicate all the gas seeps mapped from integrated multibeam acoustic water column data. Pink dots labelled 1-6 display the locations of seeps that were surveyed using the singlebeam echosounder. The three white boxes A-C show the locations where bubble size measurements were made. Bubble rise rate measurements were made at Seep 1 . The inset panel shows details of the bathymetry as a shaded relief map, located by the red square on the main figure. (For interpretation of the references to colour in this figure legend, the reader is referred to the web version of this article.)

camera. The techniques used in this study were designed for measuring bubbles that are rising vertically. The DTIS footage in this study showed that in practice, bubbles often do not rise vertically as they are subject to ocean currents and turbulence. Any deviation of a bubble towards or away from the camera will make the observed bubble appear smaller and higher, or larger and lower, respectively, as illustrated in Fig. 3A. We apply a deviation uncertainty factor to our bubble measurements as defined in the following paragraph as there is no way of directly measuring the depth of field in the DTIS footage.

To estimate a reasonable uncertainty factor that accounts for the horizontal deviation of a rising bubble in and out of the camera view, we use DTIS footage of the horizontal deviation of bubble sizes across the camera's field of view (Fig. 3B-D). We use the DTIS-recorded seeps to measure bubble size ranges at increasing/different bubble heights for the three seeps used in this study. A maximum likely bubble deviation for increasing height above the seafloor can be obtained from these seeps, allowing us to fit an equation to derive an elevation-dependent uncertainty.

\subsection{Combining size, rise rates and intensity to estimate flow rates}

We calculate the flow rate of methane bubbles using the inverse hydroacoustic method, automated in the Matlab 'FlareFlow' module (Veloso et al., 2015). We analysed six flares that we surveyed with 

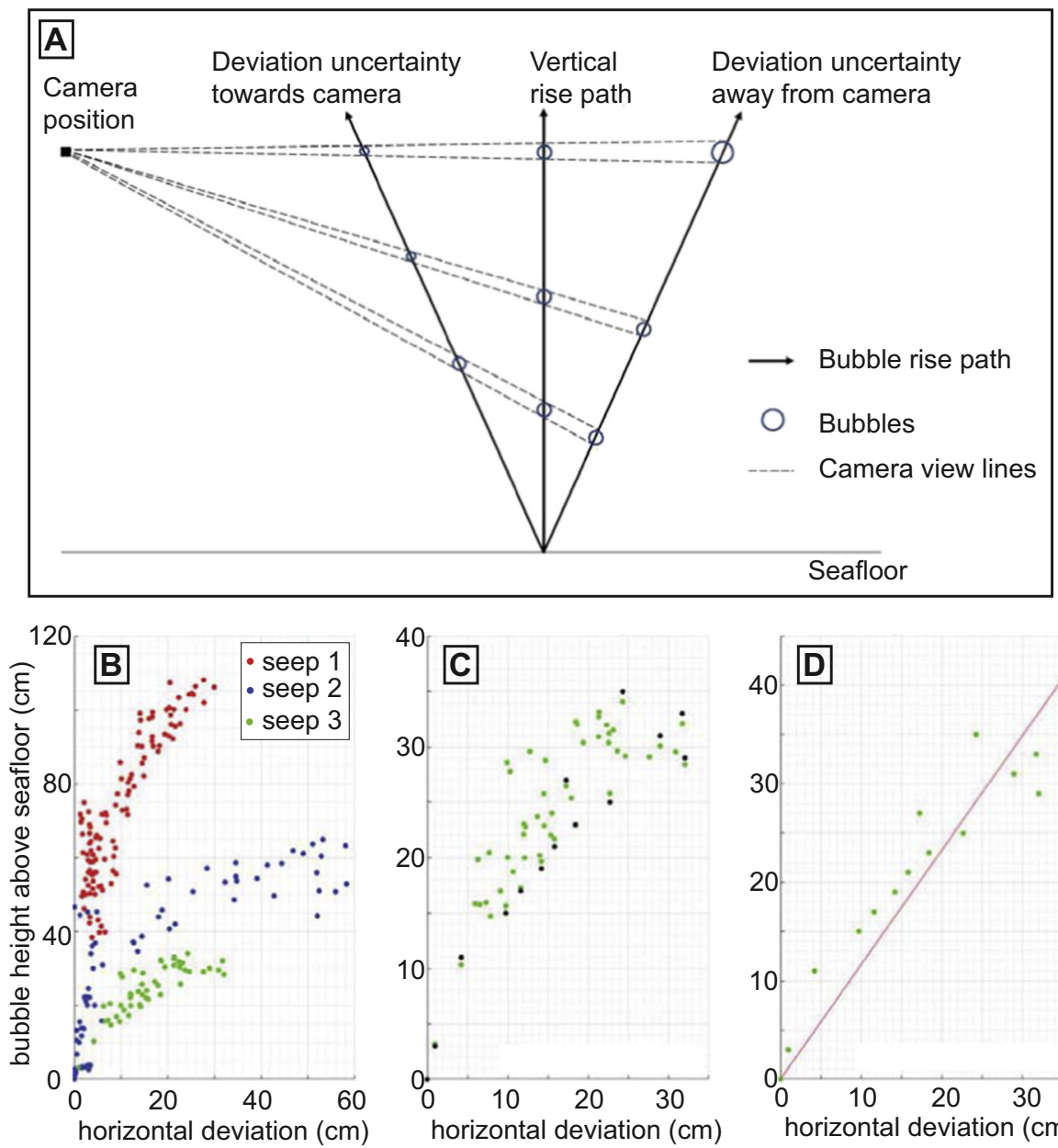

Fig. 3. A) Cross-sectional schematic of how bubbledeviation uncertainty towards and away from the camera is applied in calculations. Bubbles that have deviated away from the camera are larger and closer to the seafloor than they would appear if assumed they had risen vertically. The converse is true for bubbles that have deviated towards the camera. B) Horizontal bubble deviation across the camera's field of view at Seeps 1-3. C) Maximum bubble deviation plotted against height above the seafloor for Seep 3 (green dots) with the maximum bubble deviation for $2 \mathrm{~cm}$ binned data (black dots). D) Linear trendline fit $(y=1.62 \times)$ through the maximum bubble deviations at Seep 3. (For interpretation of the references to colour in this figure legend, the reader is referred to the web version of this article.) single beam echosounder (Fig. 2). The acoustic signatures of these flares are shown in Fig. 4. Flare point data are vertically cropped to a specified depth window for estimating flow rates. In this study, we have chosen a window $5-10 \mathrm{~m}$ above the seafloor to be as close as possible to the source, while avoiding reverberation effects of the signals at the seafloor (Veloso et al., 2015).

Our derived bubble rise rates are loaded into the FlareFlow module for the bubble sizes present and used in addition to the published inbuilt bubble rise rates. Water temperature, salinity and density were acquired from local conductivity-temperature-depth profiles for estimating the gas density at the respective water depth $\left(\rho_{G}\right)$. Sound speed was acquired using a velocity profiler. Surface tension and viscosity were correlated with environmental information using the relationship of Miyake and Koizumi (1948). Gaseous methane constants including specific heat capacity (Din, 1961; Rueff et al., 1988), specific heat ratio (Din, 1961), thermal conductivity (Prasad et al., 1984) and gas density at atmospheric pressure were entered into the module. Pressure acting on the bubble is derived from the depth of the bubble measured by the echosounder.

It is known that the presence of contaminants on bubble surfaces (termed 'dirty bubble' as opposed to a 'clean bubble') suppresses bubble-surface oscillations, and slows down bubble ascent (Datta et al., 1950). To determine whether the measured bubbles have a contaminant cover, we compare the obtained BRDs with published BRDs from both dirty and clean bubbles.

All the above mentioned parameters are used to calculate the mass bubble flow rate $\left(\emptyset_{\mathrm{M}}\right.$; full methodology detailed in Veloso et al. (2015)).

\subsection{Seep identification}

We used MBES water column processing tools available in SonarScope (c.f. Dupré et al., 2015) to identify seep locations over the entire survey area. Potential gas seepage sites are identified by anomalously high acoustic backscatter values in vertically-summed intensity maps of the MBES water column data. High acoustic backscatter values can indicate gas seep plumes but may also represent artefacts or biological features, e.g. fish or the deep scattering layer. What we identify as a gas seep from vertically summed-intensity maps of the MBES water column data is likely to reflect an aggregate of gas bubble seepage points. As the vertically-summed intensity maps integrate high watercolumn backscatter signal to the seafloor, any gas seep imaged multiple times by separate survey passes would plot in the same place. This removes the potential to map the same site more than once.

Typically, side-lobe artefacts are created by later-arriving echoes from outer regions of the acoustically surveyed seafloor (Chadwick et al., 2014; Urban et al., 2017) and these have been filtered from the data using the side-lobe compensation tool in SonarScope. Nadir reflections are apparent as high-amplitude zones that run along the centre of sonar lines, created from the near-direct reflections of acoustic energy (Tang et al., 2005). To remove the central noise spike across the entire survey area, we acquire the series of across-track summed echo intensity values for a succession of pings that recorded no observable seep activity. The across-track summed intensity values are averaged across the pings to produce a curve of intensity values that represents the expected signal return for an area of seafloor without seeps. The high-amplitude nadir reflection energy is well represented in the averaged curve, which is subtracted from each ping in the survey area. 

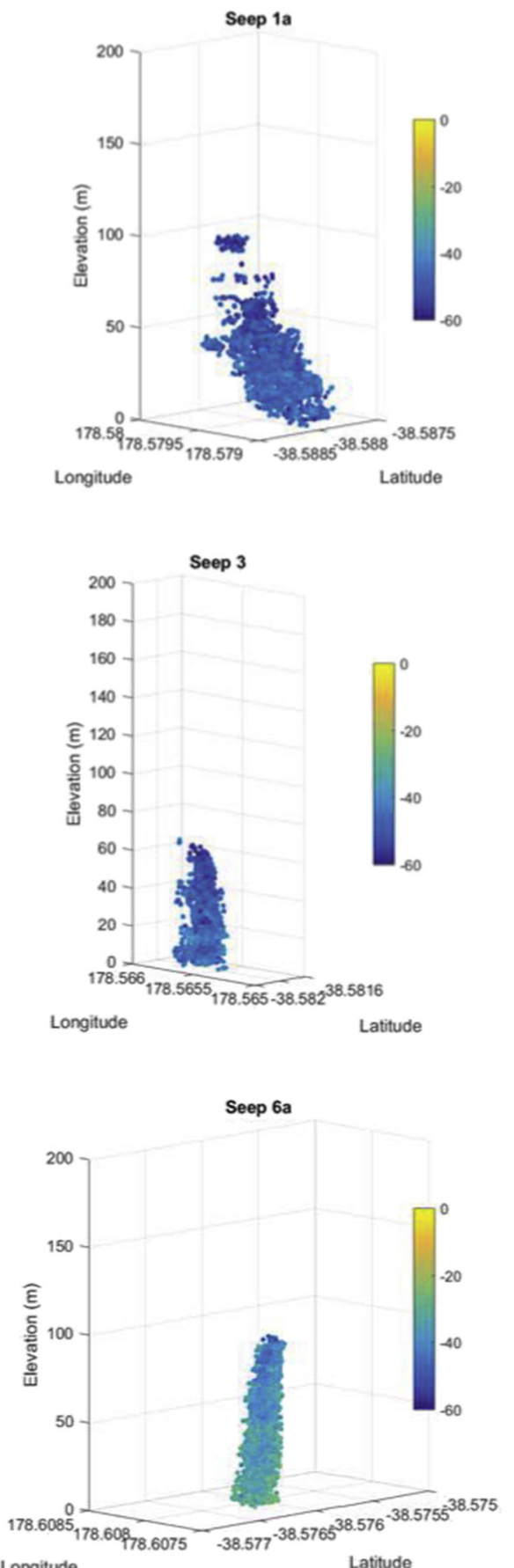

Longitude
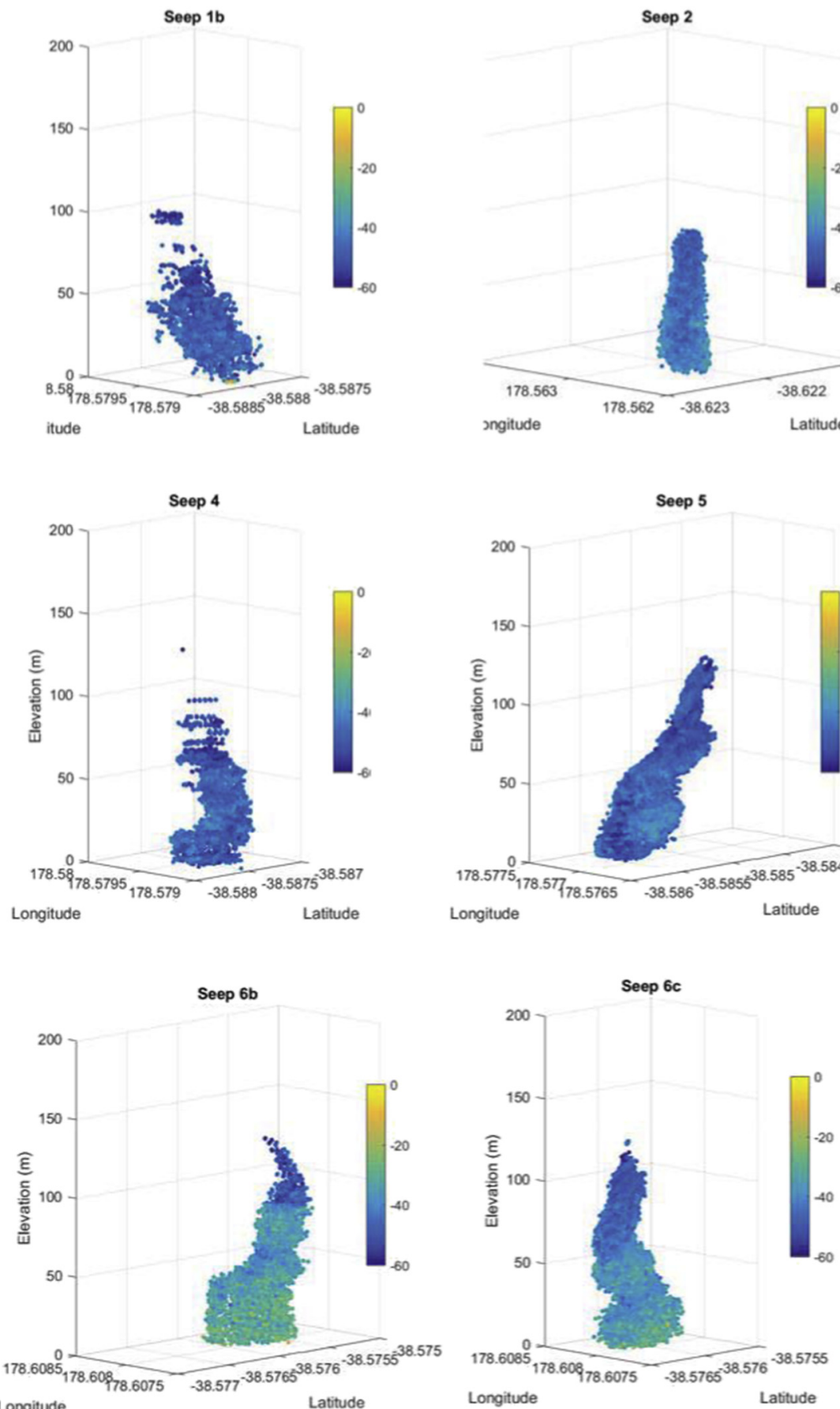

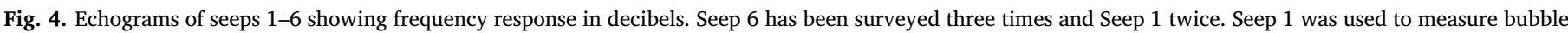
rise rates from video images.

Following the subtraction, the summed echo intensity mosaic should be approximately zero in all areas except those where there are acoustic anomalies, for example those produced by seep bubbles or biological features.

In addition, summed amplitude mosaics also contain speckled noise with individual high amplitude values being too small to constitute a bubble seep (Fig. 5). To remove the speckled noise, we applied Gaussian filtering to each high amplitude zone. The standard deviation of the Gaussian function for filtering is based on our own judgment, with the aim of selecting values that remove more of the speckled noise, but leave visible smaller zones that potentially indicate seepage.

For each identified flare/seep we also apply a threshold filter to remove low amplitude ambient water column noise. In the process of vertically summing the water column signals, deeper sections generally produce areas of higher summed intensities. Because of this, the thresholding value was adjusted for areas of different depth regions. Based on our judgment of appropriate values, we define the threshold values for each depth region/cruise section (-78 dB for TAN1505-1, -78 $\mathrm{dB}$ for TAN1404-1, -57 dB for TAN1404-2, $-57 \mathrm{~dB}$ for TAN1404-3, and -68 for TAN1404-5).

Intensity maps (Fig. 5) provide excellent information on seepage distribution for the wider area. In detail, they can be affected by current induced bending of flares resulting in a weaker and spread-out (elongated) acoustic signature displayed in the intensity maps. We did not identify this as a significant issue in our data set. After counting the seep sites we calculated the seep density across the study area at $100 \mathrm{~m}$ by 


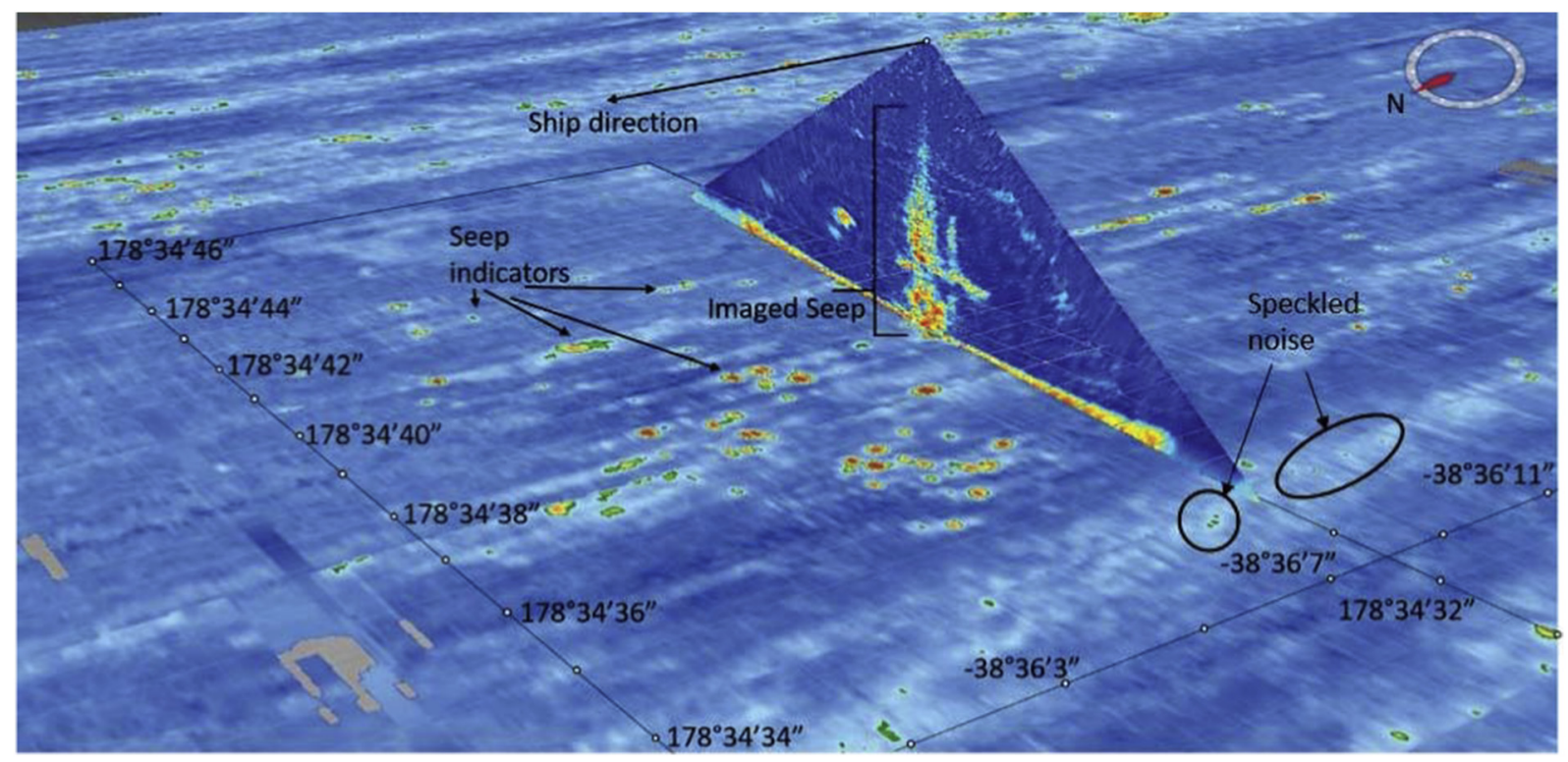

Fig. 5. A summed-intensity surface produced for part of the survey region displaying high-amplitude zones, indicating the location of seeps. This surface has been produced by vertically summing amplitude values from multibeam echograms. The summed surface can be filtered below a chosen amplitude to highlight flares, which are validated by comparing to flares visible in vertical echograms (displayed in the upright-triangular segment).

$100 \mathrm{~m}$ resolution using a $1 \mathrm{~km}$ search radius.

\section{Results}

Using the intensity maps of the survey area, we count 623 seep sites within the Tuaheni seep field. The seeps occur in $130-420 \mathrm{~m}$ water depth on the outer shelf-slope break transition, well upslope of the gas hydrate stability field (Pecher et al., 2017). Fig. 6a shows a histogram of the water depth distribution of seeps. We analysed six of the seep sites in more detail for bubble size and bubble rise rate.

\subsection{Bubble size measurements}

We made bubble-size measurements for six seeps at three different areas (Fig. 2) using multiple frames of video-recorded bubble release at the seafloor.

Bubble sizes have been grouped into $1 \mathrm{~mm}$-radius bins and normalized so that the most-common bubble-size occurrence frequency is equal to 1 (as is required for input into the FlareFlow module). For extrapolating bubble sizes between the binned BSD data in the FlareFlow calculations, we fit polynomials functions to the lower, mean and upper BSDs (Fig. 7). The order of each polynomial was selected based on the visual fit and $\mathrm{R}^{2}$ values.

\subsection{Bubble rise-rate measurements}

The height above the seafloor of three easily distinguishable bubbles from seep site 1 (Fig. 2) were recorded over a series of video frames
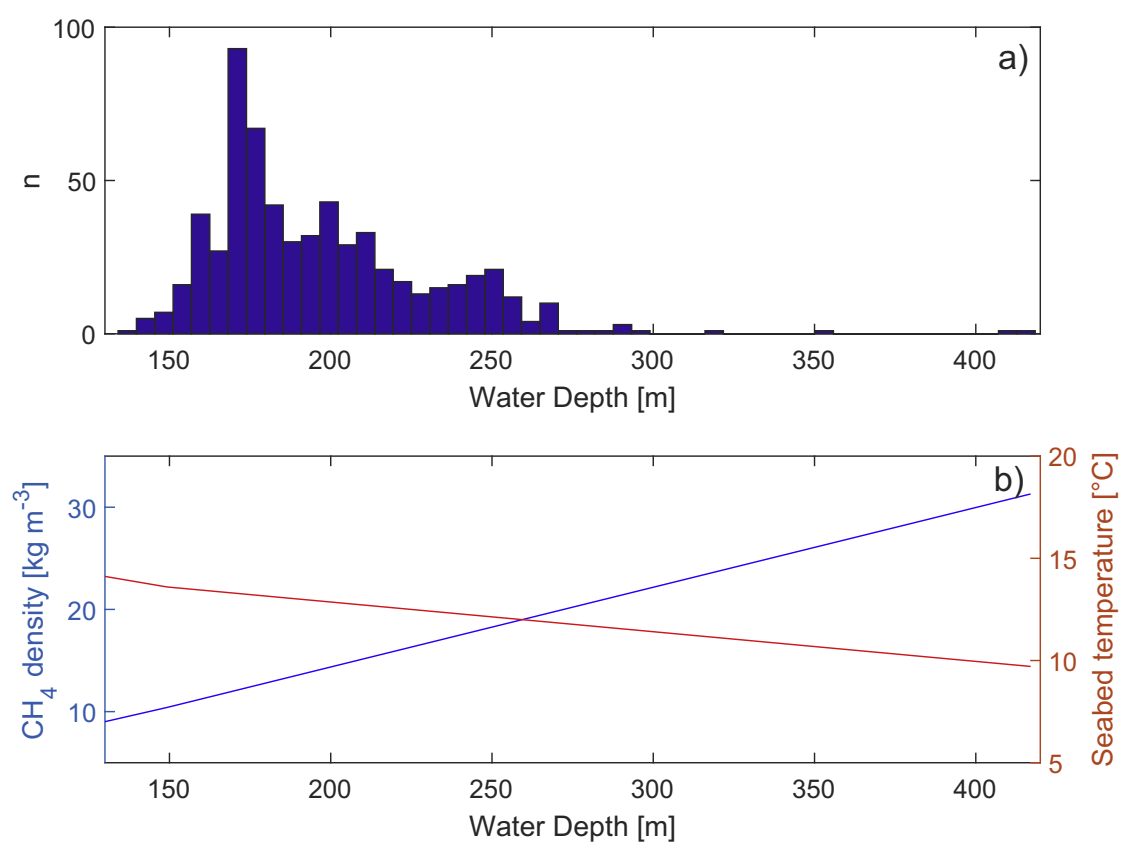

Fig. 6. a) Histogram of the number of seeps (n) occurring at different water depths. a) Curves used to calculate methane volume as a function of water depth. 


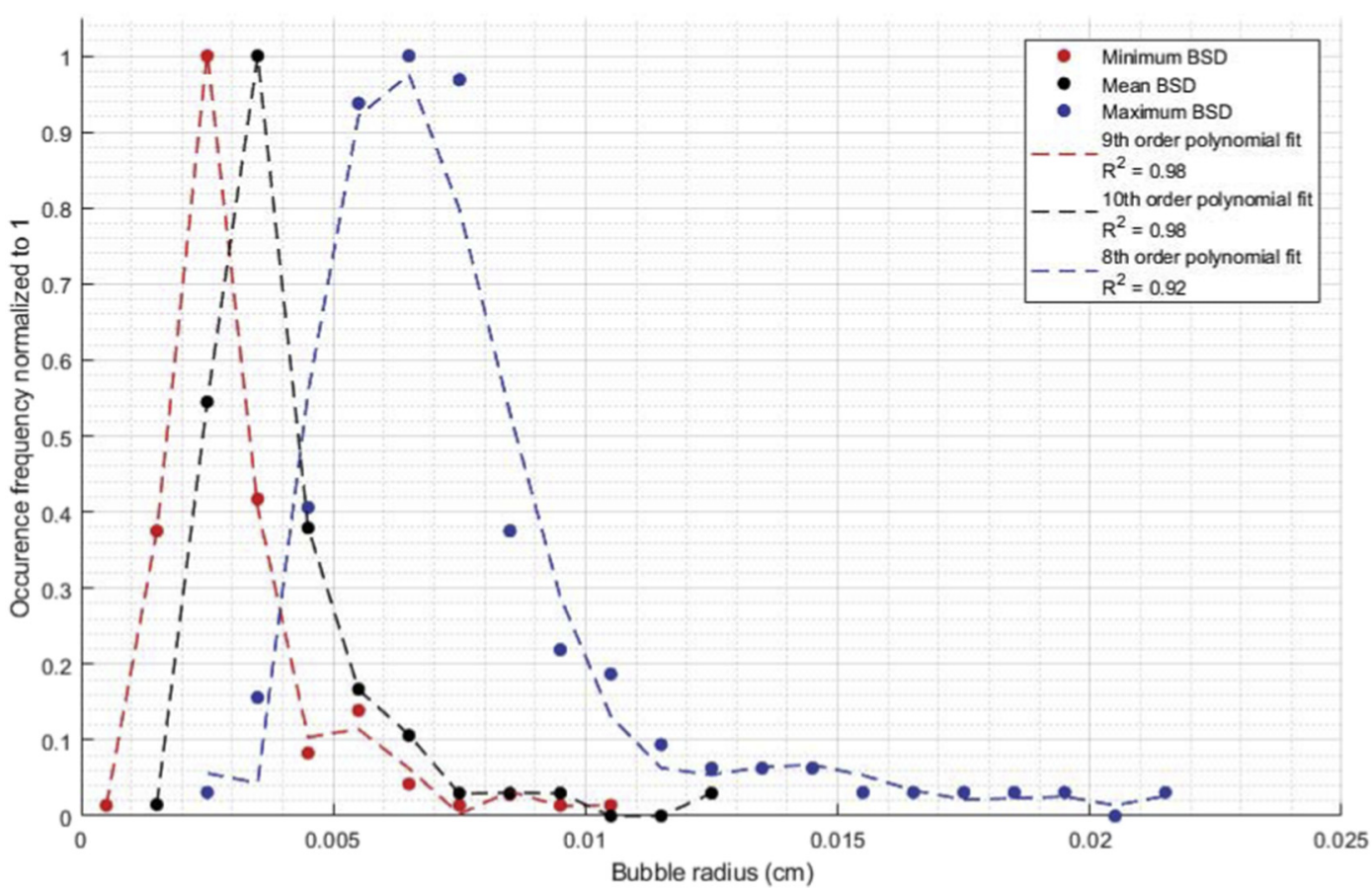

Fig. 7. Minimum, mean and maximum bubble-size distribution measurements, normalized to a maximum occurrence frequency of 1 (as required for calculating flow rate in FlareFlow). Polynomial fits used for flow calculations are plotted, annotated with order and $\mathrm{R}^{2}$ values.

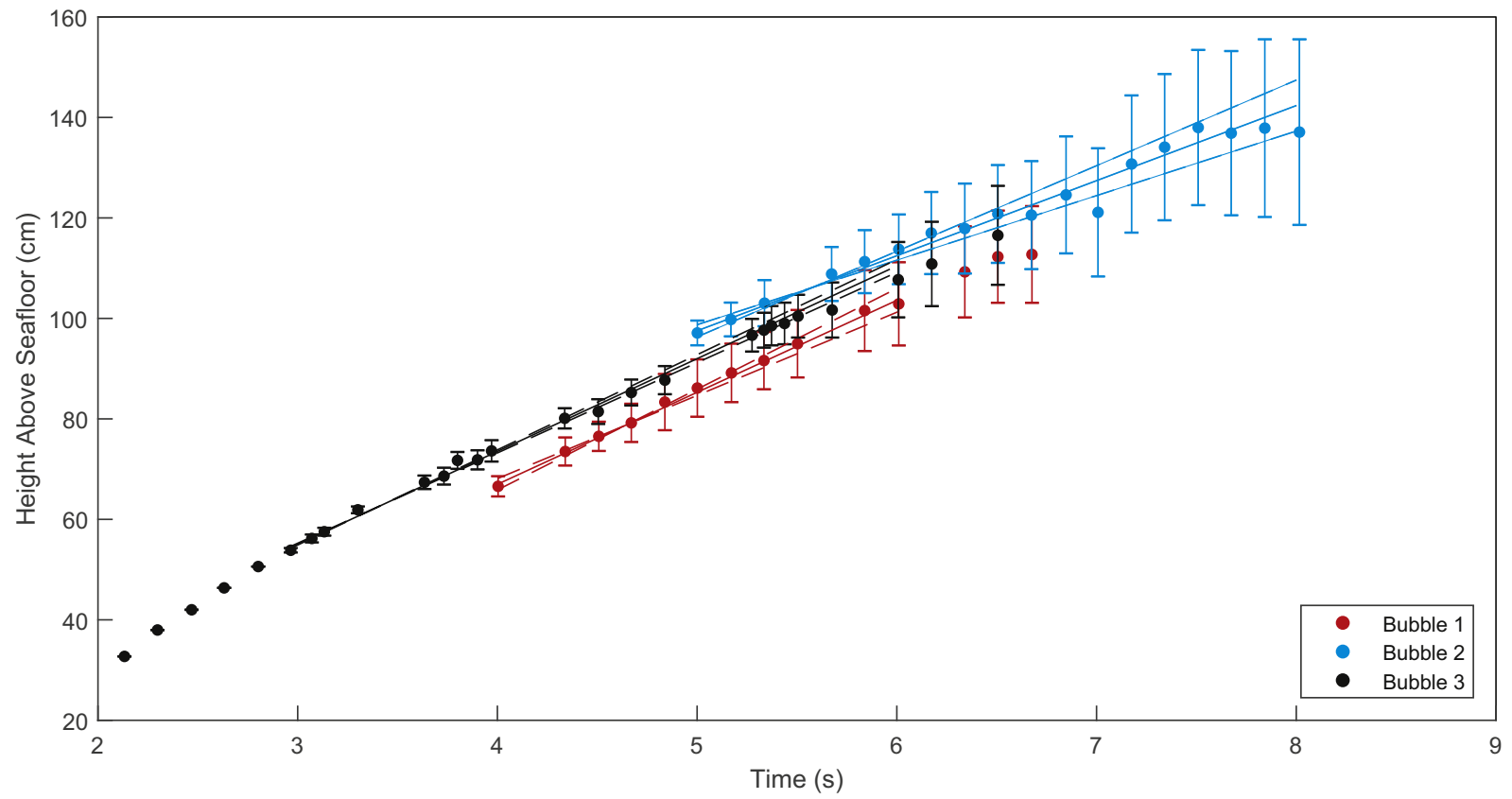

Fig. 8. Elevation distances above the seafloor have been acquired for bubbles 1 (red), 2 (black) and 3 (blue) with maximum and minimum uncertainty values. Linear trends have been fitted to all of the data series, except for early measurements of bubble 3, where the curved trend shows where the bubble is yet to reach its terminal rise velocity. The line equations and Weighted Correlation Coefficient of each linear trend is given in Table 2. (For interpretation of the references to colour in this figure legend, the reader is referred to the web version of this article.)

Table 1

Weighted least-squares fit equations to bubble rise-rate measurements. WCC is Weighted Correlation Coefficient. ESR is Equivalent Spherical Radii.

\begin{tabular}{llllll}
\hline & Least squares fit & WCC & St. Dev. Slope & St. Dev. y-intercept & ESR \\
\hline Bubble 1 & $18.3 \mathrm{x}-6.2$ & 0.999 & 1.8 & 8.3 & 5.3 \\
Bubble 2 & $14.9 \mathrm{x}+23.1$ & 0.993 & 2.2 & 12.1 & 4.2 \\
Bubble 3 & $18.5 \mathrm{x}-0.6$ & 0.998 & 0.5 & 1.6 & 5.4 \\
\hline
\end{tabular}

(Bubbles 1, 2 and 3 in Fig. 8). The elevations of these bubbles above the seafloor are plotted in Fig. 8 with associated uncertainty estimates. Linear least-squares fits provide a good representation of the bubble height data and associated errors $\left(\mathrm{R}^{2}\right.$ values $0.999,0.993,0.998$ for bubble 1, 2 and 3 respectively), which implies that these bubbles rose at a constant speed over the period of observation. The equivalent spherical radii of Bubble 1, 2 and 3 are $5.3 \mathrm{~mm}, 4.2 \mathrm{~mm}$ and $5.4 \mathrm{~mm}$, respectively. We take the slope of each least-squares fit equation to derive rise-rates of $18.3 \pm 1.8 \mathrm{~cm} / \mathrm{s}$ (Bubble 1), $14.9 \pm 2.2 \mathrm{~cm} / \mathrm{s}$ (Bubble 2), 
Table 2

Calculated flow rates for the 6 seep sites analysed in this study. Values for each seep pass represent an average of 5 different bubble rise rate curves, including the one measured in this study. BSD is the Bubble Size Distribution.

\begin{tabular}{lllll}
\hline Seep & $\begin{array}{l}\text { Water } \\
\text { depth }(\mathrm{m})\end{array}$ & $\begin{array}{l}\text { Flow rate (mL/ } \\
\text { min), min BSD }\end{array}$ & $\begin{array}{l}\text { Flow rate (mL/ } \\
\text { min), mean BSD }\end{array}$ & $\begin{array}{l}\text { Flow rate (mL/ } \\
\text { min), max BSD }\end{array}$ \\
\hline 1a & 159 & 6.6 & 7.9 & 30.7 \\
1b & & 41.2 & 49.0 & 180.8 \\
2 & 161 & 40.0 & 47.8 & 187.6 \\
3 & 186 & 7.6 & 9.0 & 35.1 \\
4 & 149 & 3.0 & 3.5 & 13.8 \\
5 & 154 & 8.9 & 10.3 & 40.1 \\
6a & 178 & 301.1 & 352.7 & 1405.0 \\
6b & & 482.3 & 575.7 & 2249.0 \\
6c & & 198.2 & 236.7 & 924.9 \\
1st quartile & NA & 6.5 & 7.7 & 29.8 \\
Median & NA & 16.4 & 19.4 & 72.9 \\
3rd quartile & NA & 111.8 & 133 & 522.3 \\
\hline
\end{tabular}

and $18.5 \pm 0.5 \mathrm{~cm} / \mathrm{s}$ (Bubble 3) (Table 1).

\subsection{Methane flow rate calculations}

Singlebeam derived flare profiles of Seeps 1 to 6 were used to calculate flow rate ranges using maximum and minimum BSD (Table 2). We modified the original FlareFlow module so that the BSD is calculated for a second-order Gaussian fitted function rather than a polynomial fit, in agreement with Leifer and Culling (2010) for BSDs of minor seeps. As our calculated BRDs are at the low end of published values we incorporate published data to make flow rate calculations for all seeps in FlareFlow. We take an average of these calculations to estimate gas flow rates. For seeps 1 to 5 we get gas flow rates between 3.0 and $187.6 \mathrm{~mL} / \mathrm{min}$ (Table 2). Seep 6 produces higher flow rates than the other 5 seeps. This seep was resurveyed three times to provide lownoise profiles that we used to calculate gas flow rates between 198.2 and $2249.0 \mathrm{~mL} / \mathrm{min}$. Combining all the calculated flow rates from the six seeps produces a positively skewed distribution on account of the higher flow rates from Seep 6. As such, we use quartiles (first quartile, median and third quartile) to represent the statistical distribution of values (Table 2).

\subsection{Seep density}

We have calculated the density of seeps in MBES summed intensity maps over the main area of the Tuaheni seep field (Fig. 9). We define a "seep" in this sense as a single distinct acoustic anomaly in the stacked water column data and note that each of these acoustic anomalies may well comprise more than one single bubble escape point at the seafloor. The broader seep field covers an area of approximately $90 \mathrm{~km}^{2}$. Within the centre of this region $\left(37 \mathrm{~km}^{2}\right)$ the seep density is $>2$ seeps per $\mathrm{km}^{2}$. Additionally, six regions between 1 and $2.5 \mathrm{~km}^{2}$ show seeps concentrated $>20$ seeps $/ \mathrm{km}^{2}$ (Fig. 9). While we acknowledge difficulties associated with mapping discrete seeps (i.e. individual bubble vents vs clusters of vents), these results highlight the high density of seepage over a relatively small area of seafloor.

\section{Discussion}

This study focuses on estimating the gas flow from a very dense gas seepage area on the outer shelf to upper slope of the northern Hikurangi Margin. It significantly increases the number of mapped seeps on the margin previously reported by Greinert et al. (2010) and makes a first attempt of estimating gas flow rates from such a seepage area. To do this we have integrated visual observations of bubbles with hydroacoustic single beam echosounder data.

\subsection{Bubble sizes}

Quantified bubble sizes are essential for robust gas flow rate calculations based on hydroacoustic data as they define how to interpret and model/quantify the receiver integrated acoustic signal (Artemov et al., 2007; Muyakshin and Sauter, 2010; Veloso et al., 2015; Weber et al., 2014). Other hydroacoustic studies primarily in shallow water (i.e. lakes) use only acoustic data to determine bubble size and rise rate to extrapolate flow and finally fluxes from single bubble observations (DelSontro et al., 2015; Ostrovsky et al., 2008). Acquiring accurate BSD field measurements has often been done using cameras utilising ROVs with back illuminated panels (Rehder et al., 2009; Römer et al., 2012) or small landers that are deployed on the seafloor (Greinert and Nützel, 2004; Römer et al., 2016; Schneider von Deimling et al., 2011). Camera observations are often influenced from motion blur, not enough light and, bubbles moving in and out of focus/changing distance to the camera lens in an unknown way, thereby preventing clear identification of the bubble edges when too many bubbles shadow each other. These factors may account for some of the variance apparent in the previously published bubble size distribution measurements shown in Fig. 10. Our bubble size distributions fall towards the upper end of published results and between bubble measurements obtained with video measurements in the North Pacific Ocean and the Black Sea (Fig. 10). Our size distribution shows a narrower range than other reported results as smaller bubbles are most likely not detected in our video footage due to resolution and motion blur.

\subsection{Bubble rise rates}

Fig. 11 shows bubble-rise rate measurements obtained from the time series of the three sampled bubbles 1, 2 and 3, and plotted against theoretical methane-bubble rise rates constructed for clean and dirty bubbles. Within the uncertainty limits our empirical estimates of bubble-rise rates overlap with those of Leifer et al. (2000a) for dirty bubbles, however our rates are consistently slower than theoretical predictions published by others (Leifer and Patro, 2002; Leifer et al., 2000b; Mendelson, 1967; Woolf, 1993; Woolf and Thorpe, 1991). For calculating flow rates we have therefore taken an average of the published dirty bubble models and our rise rate measurements.

We established that bubbles 1, 2 and 3 are each ascending at their respective terminal velocities (Fig. 8) enabling comparison to the theoretical models in Fig. 11 that are also based on terminal velocities. As the bubble size and acceleration estimates are consistent with those of other models, we are confident there is a physical explanation (rather than a systematic measurement error) for the disparity between the theoretical rise rates and our observation-based rise rate estimates.

Leifer et al. (2000a) suggested that bubble-rise rates are overestimated in theoretical models due to assumptions made in dirtybubble theoretical rise-rate models that neglect the slowing effects of bubble oscillations. Oscillations slow a bubble's ascent because energy from its ascent is transferred into perpendicular oscillatory motions. Surfactants on/around bubble surfaces suppress these oscillations; most bubble rise velocity models neglect oscillations of dirty bubbles, assuming that they behave like solid spheres. Such an assumption may only be valid for bubbles of $r<600 \mu \mathrm{m}$ where oscillations are negligible (Leifer et al., 2000a). This slowing effect has not been taken into account for the models plotted in Fig. 11 and it is possible that the differences in observed and predicted values are because of this oscillation effect. By shifting the model of Leifer et al. (2000a) along the ordinate to slower values, we estimate that oscillation may account for an overestimation of the theoretical rise model between 1.1 and $2.1 \mathrm{~cm} / \mathrm{s}$. 


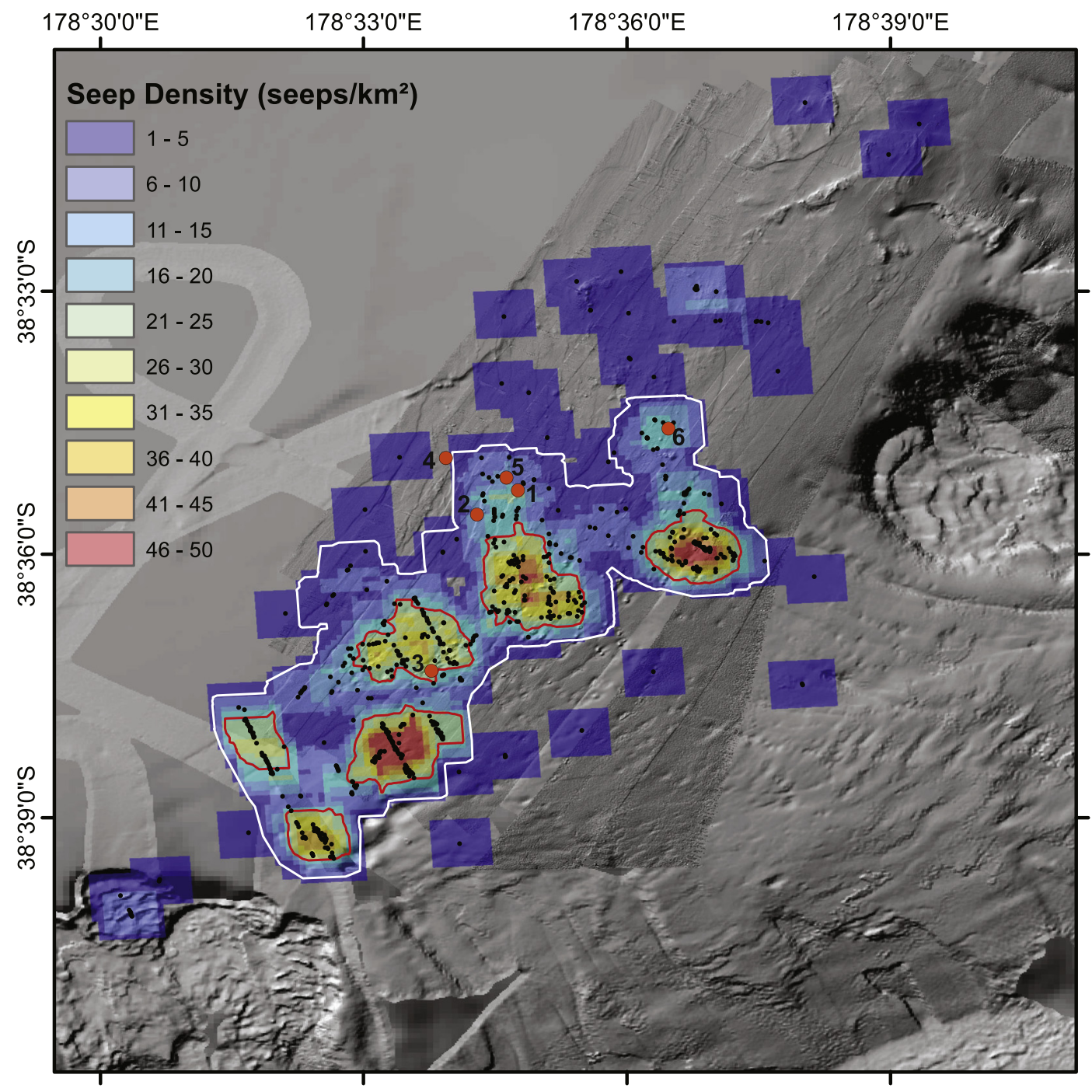

Fig. 9. Mapped seep density in the Tuaheni seep field. Individual mapped seeps are shown as black dots and red dots show seeps surveyed using the singlebeam echosounder as in Fig. 2. Seep density is shown in seeps per $\mathrm{km}^{2}$ based on a $1 \mathrm{~km}$ roaming window analysis. The white and red contour lines show a density of 2 and 20 seeps per $\mathrm{km}^{2}$, respectively. (For interpretation of the references to colour in this figure legend, the reader is referred to the web version of this article.)

\subsection{The Tuaheni seep field in the context of the Hikurangi subduction margin}

Prior to this study, the state of knowledge of methane seepage on the Hikurangi margin was most recently summarized by Greinert et al. (2010). The context of methane seepage in terms of accretionary wedge tectonics and the gas hydrate system has been described in a regional sense by Barnes et al. (2010).

Greinert et al. (2010) documented evidence for methane seepage in six broad areas along the length of the Hikurangi Margin, from South to North: Opouawe Bank, Uruti Ridge, Porangahu Ridge, Omakere Ridge, Rock Garden, Ritchie Ridge. Across these six regions, they identified a total of 36 individual seep sites. Opouawe Bank could be characterized as having the most-dense distribution of methane seeps, with 14 seeps mapped over an area of $\sim 25 \mathrm{~km}^{2}$ (i.e. an average of less than one seep per $\mathrm{km}^{2}$ ).

Barnes et al. (2010) describe how the seeps sites, typically occurring within water depths of 700-1200 m, exhibit a close relation to thrust ridges and underlying seaward-vergent thrust faults. They concluded that the thrust faults act as preferred fluid flow conduits, and that an inner foundation of Cretaceous to Paleogene rocks might act as a broad permeability barrier that focusses fluid flow to its outer edge. Barnes et al. (2010) also noted conspicuous breaks in the continuity of BSRs beneath seeps on thrust ridges, as well as shallow fault networks within the gas hydrate stability zone that act as fluid conduits in the shallowest sub-seafloor section. These shallow sub-seafloor fluid migration pathways have been described in more detail in subsequent high-resolution 3D seismic surveys of particular thrust ridges (Plaza-Faverola et al., 2014; Riedel et al., 2018).

The Tuaheni seep field is distinctly different from these previously described areas. First, it is located in much shallower water depths (130-420 m, Fig. 6a) that are well above the up-dip limit of gas hydrate stability on this margin. Second, the density of individual seeps is much greater than previously observed on the Hikurangi margin. The Tuaheni seep field has regions as large as $2.5 \mathrm{~km}^{2}$ that have a seep density of $>20 \mathrm{seeps} / \mathrm{km}^{2}$ (Fig. 9). This is the mostly densely-populated seep field yet documented on the Hikurangi Margin, comprising more than an order-of-magnitude more seeps than previously known, raising the question of why is there such a dense population of active seepage in this small area away from the local tectonic setting where previous seepage sites have been documented?

The Tuaheni seep field occurs on a localised section of the Hikurangi subduction margin where several anomalous processes have been documented. 1) historical silent or tsunami earthquakes have been linked to seamount subduction directly beneath the region of the Tuaheni seeps (Bell et al., 2014); 2) repeated slow slip is centred in this 


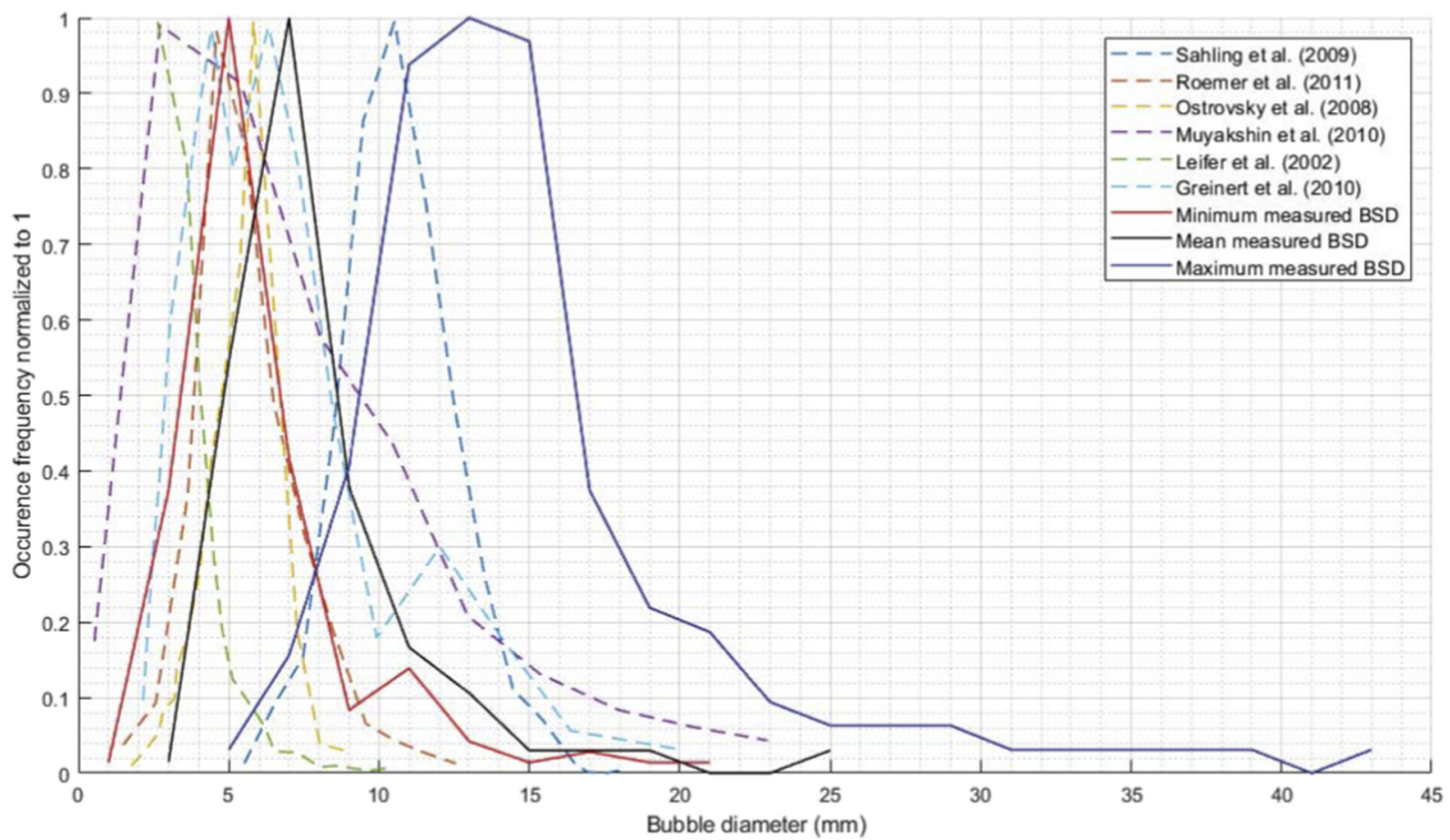

Fig. 10. Minimum, mean and maximum Bubble Size Distributions (BSDs) measured for this study plotted with published BSDs.

region (Wallace et al., 2016); and 3) a prominent double BSR, indicating an unstable/transient gas hydrate system, occurs immediately downslope of the seeps area (Pecher et al., 2017); 4) a network of small offset extensional faults occurs across the seepage area (Böttner et al., 2018). The seeps also occur seaward of high uplift-rate outer shelf splay faults (Mountjoy and Barnes, 2011). The processes 1-4 listed above have been inferred to be related to a mix of anomalous fluid behaviour in the plate interface and upper plate and localised tectonic deformation. Seamount subduction has also been invoked as playing a role in deformation/fluid processes (Bell et al., 2014). The seeps in the Tuaheni seep field may reflect the same localised fluid source and/or tectonic deformation invoked as responsible for the tsunami earthquakes, double BSR and extensional deformation. Conceptually, this high-density seepage field could be the product of focussed secondary permeability due to rapid uplift and extensional deformation leading to fluid focusing, and possibly combined with enhanced fluid production at depth. The position at the shelf to slope transition sets it apart from other documented seep sites on the margin where fluid seepage is mostly focused around thrust fault propagated anticlines at the boundary between the active accretionary wedge ad the deforming backstop (Barnes et al., 2010). Our results provide a first step towards understanding this fluid system in terms of the density of seeps and the

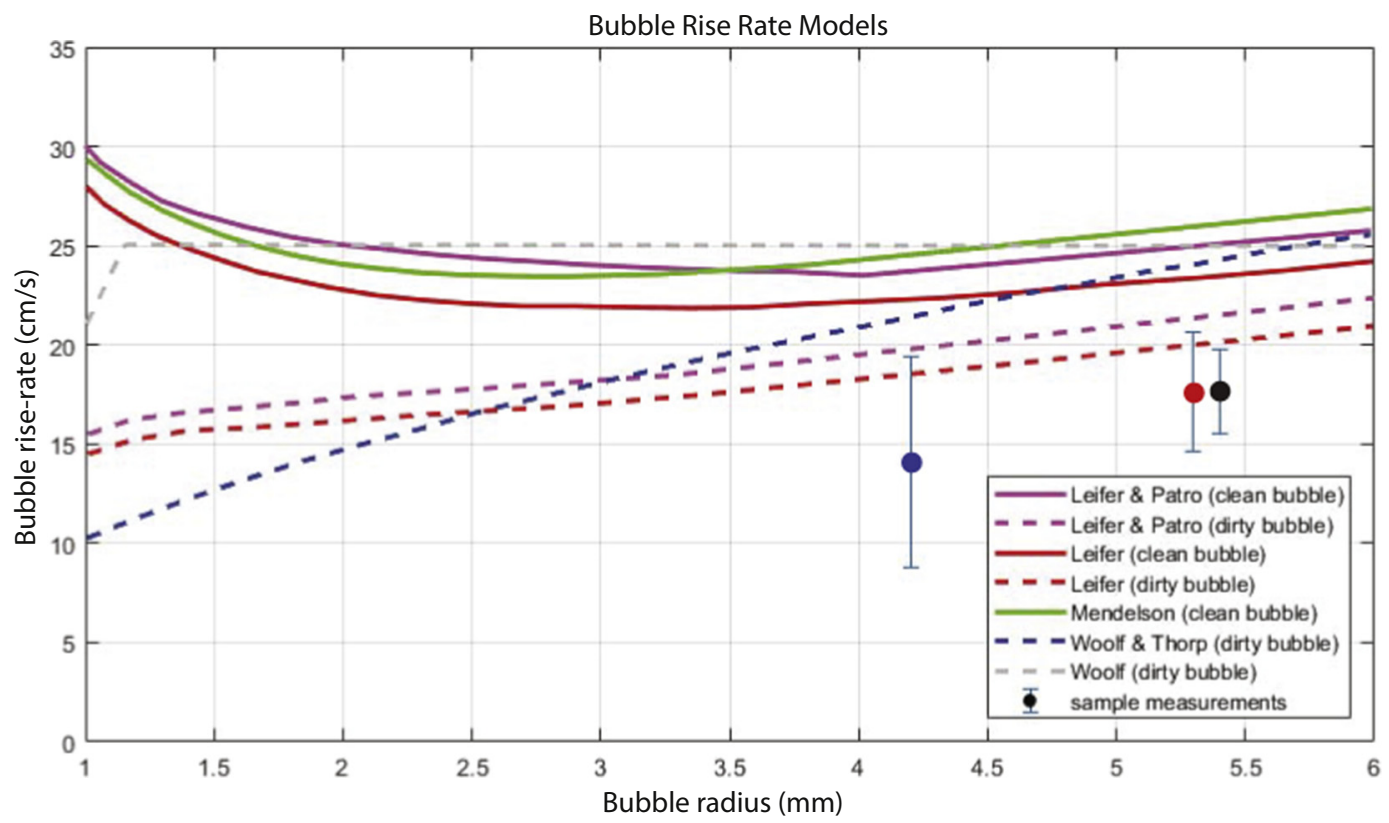

Fig. 11. Bubble Rise Rates derived in this study plotted against published theoretical models for bubble-radius dependant rise speeds (Leifer et al., 2000a; Leifer and Patro, 2002; Mendelson, 1967; Woolf and Thorpe, 1991). 
Table 3

Mean flow rates $(\mathrm{mL} / \mathrm{min})$ for each of the six seeps analysed, based on mean bubble size distributions and bubble rise rates (see Table 2). Pressure (P, in MPa) at the seafloor is calculated assuming a seawater density of $1025 \mathrm{~kg} \mathrm{~m}^{-3}$. Temperature $\left(\mathrm{T}\right.$, in $\left.{ }^{\circ} \mathrm{C}\right)$ at the seafloor is taken from CTD casts at each of the six seeps. Density of methane $\left(\rho \mathrm{CH} 4, \mathrm{~kg} \mathrm{~m}^{-3}\right)$ at the given $\mathrm{P}$ and $\mathrm{T}$ is calculated after Kossel et al., 2013. $\mathrm{Kg}_{\text {year }}{ }^{-1}$ is calculated from the density and the mean flow rate.

\begin{tabular}{lllllll}
\hline Seep no. & $\begin{array}{l}\text { Water } \\
\text { depth (m) }\end{array}$ & $\begin{array}{l}\text { Mean flow } \\
(\mathrm{mL} / \mathrm{min})\end{array}$ & $\mathrm{P}(\mathrm{MPa})$ & $\mathrm{T}\left({ }^{\circ} \mathrm{C}\right)$ & $\begin{array}{l}\rho \mathrm{CH}_{4} \\
\left(\mathrm{~kg} \mathrm{~m}^{-3}\right)\end{array}$ & $\begin{array}{l}\mathrm{Kg} \mathrm{CH}_{4} \\
\text { year }^{-1}\end{array}$ \\
\hline 1 & 159 & 28.5 & 1.60 & 13.5 & 11.14 & 142 \\
2 & 161 & 47.8 & 1.62 & 13.4 & 11.36 & 244 \\
3 & 186 & 9.0 & 1.87 & 13.1 & 13.26 & 54 \\
4 & 149 & 3.5 & 1.50 & 13.6 & 10.43 & 16 \\
5 & 154 & 10.3 & 1.55 & 13.5 & 10.80 & 50 \\
6 & 178 & 388.3 & 1.79 & 13.2 & 12.65 & 2145 \\
\hline
\end{tabular}

gas flow rate from them. Further work on the geology and tectonics is required to understand the origin of the fluids and local tectonic conditions that have resulted in this highly focused seepage field that will have implications for understanding fluid systems on this margin and other subduction margins globally.

\subsection{Estimate of total methane flow into the ocean at the Tuaheni Seep Field}

Although there is high uncertainty in extrapolating flow rates from selected seep sites to a much larger population of seeps, it is worthwhile to make first order estimates of the amount of methane being released on a larger scale. To estimate the range of likely release, we take the median and first and third quartile methane flow rates for Seeps 1-6, based on a range of BSD (Table 2). In Table 3 we show how the flow rate for each of the six seeps (assuming the mean BSD) translates to a mass of methane expelled per year. This conversion to mass of methane ( $\mathrm{kg} /$ year) is made by correcting for gas compressibility at the given water depth (pressure) and temperature (Kossel et al., 2013) (Table 3). The water bottom temperature that we use (Fig. 6b) is based on conductivity-temperature-depth (CTD) casts carried out during the surveys.

If we assume that these 6 seeps are a representative sample of the entire seep field, we can make an estimate of the mass of methane released from the entire seep field (623 mapped seeps, Fig. 6a). To do this, we consider the median flow rate of $19.4 \mathrm{~mL} / \mathrm{min}$ as well as the first quartile from a minimum BSD $(6.5 \mathrm{~mL} / \mathrm{min})$ and the third quartile from a maximum BSD $(522.3 \mathrm{~mL} / \mathrm{min})$ (Table 2). These values represent the widest spread of first and third quartiles as they encompass minimum to maximum BSD assumptions (Table 2). For our best estimate of methane release from the entire seep field, we assume that each of the 623 seeps produces the median flow rate. Correcting for gas compressibility (Kossel et al., 2013), this equates to $90 \mathrm{t}$ of methane per year. To account for the uncertainty in the flow rate calculation, we use the first and third quartile values for flow rates from these six seeps (i.e. $6.5 \mathrm{~mL} / \mathrm{min}$ and $522.3 \mathrm{~mL} / \mathrm{min}$, respectively; Table 2) and extrapolate them to the entire seep field, again correcting for gas compressibility. This yields a range of $\sim 30$ to $2415 t$ of methane per year. We note that these estimates do not account for the ephemeral nature of seepage as we have no data to calculate this, and are therefore estimates from a snap shot in time (they assume a constant flow rate through the year).

Our results show the Tuaheni seep field is a very productive geological source of methane into the ocean and, given the shallow water depths, potentially into the atmosphere. The seep field occurs in a relatively small area and so the impact on the local ocean environment could be significant. Further work is required to determine what the direct impact on the ocean is, and if methane in significant amounts reaches the ocean surface.

\section{Conclusions}

We have mapped 623 gas bubble seeps in the Tuaheni seep field off New Zealand's East Coast by depth integrating multibeam acoustic water column data. The seep field occurs at the shelf to slope transition of the Hikurangi Margin in water depths between 130 and $420 \mathrm{mbsl}$, away from any documented large upper plate faults. The seeps occur within an area of $\sim 90 \mathrm{~km}^{2}$, however the distribution of seep sites is highly variable with most seeps concentrated in a smaller region where seep density exceeds 20 acoustically-distinct seeps per $\mathrm{km}^{2}$ - this is by far the highest spatial density of gas seeps currently known on the Hikurangi margin. The presence of a double BSR has been used previously to infer rapid uplift in this region; the seep field may be related to this uplift and an associated fluid system.

We have advanced the development of techniques for estimating the methane outputs of submarine seeps and applied them to the Tuaheni seep field. Bubble sizes measured by applying Canadian Grids to video footage are in general agreement with previously published bubble-size results. We have measured bubble rise rates at one location and find these are at the lower end of published rise rates. We therefore include published rise rate curves with our results to enable a robust assessment of gas flow rates.

Our calculated bubble-size and rise-rate distributions have been combined with the FlareFlow module developed by Veloso et al. (2015) to obtain methane flow rates from the seep field. Flow rate calculations reveal that most seeps in the study area release between $\sim 3$ and $\sim 190 \mathrm{~mL} / \mathrm{min}$ of methane. There is also evidence for more prominent seeps within the survey area that release methane at rates of between $\sim 200$ and $\sim 2250 \mathrm{~mL} / \mathrm{min}$. We extrapolate these flow rate values to the whole seep field and using a median flow rate estimate a total output of $\sim 90 \mathrm{t}$ of methane per year.

The techniques we presented here offer a means of determining bubble size distributions without the need for expensive ROVs. We have demonstrated that the technique can be used for calculating methane flow rate in combination with calibrated acoustic survey data and foresee broad application of these techniques as large numbers of gas seeps are being discovered with the widespread availability of ship mounted multibeam echosounder technology.

\section{Acknowledgements}

Ben Higgs received financial assistance from the George Mason Charitable Trust Scholarship, the Victoria University of Wellington Masters publication scholarship, and the Lithgow Family Trust Scholarship. We are grateful to Mario Veloso for giving us access to the FlareHunter and FlareFlow Module matlab codes. We thank the officers and crew of the RV Tangaroa on the TAN1404 and TAN1505 surveys. Joshu Mountjoy and Gareth Crutchley are funded by NIWA SSIF funding in the Coasts and Oceans Programme and GNS Science SSIF funding, respectively, and by Royal Society of New Zealand Marsden Fund, New Zealand Grant NIW1603.

The Matlab code used here can be from Pangea (https://doi. pangaea.de/10.1594/PANGAEA.904138).

\section{Appendix A. Supplementary data}

Supplementary data to this article can be found online at https:// doi.org/10.1016/j.margeo.2019.105985.

\section{References}

Artemov, Y.G., Egorov, V., Polikarpov, G., Gulin, S., 2007. Methane Emission to the Hydroand Atmosphere by Gas Bubble Streams in the Dnieper Paleo-Delta, the Black Sea.

Barnes, P.M., Nicol, A., Harrison, T., 2002. Late Cenozoic evolution and earthquake potential of an active listric thrust complex above the Hikurangi subduction zone, New Zealand. Geol. Soc. Am. Bull. 114 (11), 1379-1405. 
Barnes, P.M., Lamarche, G., Bialas, J., Henrys, S., Pecher, I., Netzeband, G.L., Greinert, J., Mountjoy, J.J., Pedley, K., Crutchley, G., 2010. Tectonic and geological framework for gas hydrates and cold seeps on the Hikurangi subduction margin, New Zealand. Mar. Geol. 272 (1), 26-48.

Bashkatov, A.N., Genina, E.A., 2003. Water refractive index in dependence on temperature and wavelength: a simple approximation. In: Proceedings Saratov Fall Meeting 2002: Optical Technologies in Biophysics and Medicine IV. International Society for Optics and Photonics, pp. 393-395.

Beavan, J., Tregoning, P., Bevis, M., Kato, T., Meertens, C., 2002. Motion and rigidity of the Pacific Plate and implications for plate boundary deformation. J. Geophys. Res. Solid Earth 107 (B10).

Bell, R., Sutherland, R., Barker, D.H., Henrys, S., Bannister, S., Wallace, L., Beavan, J., 2010. Seismic reflection character of the Hikurangi subduction interface, New Zealand, in the region of repeated Gisborne slow slip events. Geophys. J. Int. 180 (1), 34-48.

Bell, R., Holden, C., Power, W., Wang, X., Downes, G., 2014. Hikurangi margin tsunami earthquake generated by slow seismic rupture over a subducted seamount. Earth Planet. Sci. Lett. 397, 1-9.

Bikonis, K., Moszyński, M., Chybicki, A., Kociński, P., 2006. 3D imaging software tools for multibeam sonar data. Hydroacoustics 9, 17-22.

Böttner, C., Gross, F., Geersen, J., Crutchley, G.J., Mountjoy, J.J., Krastel, S., 2018. Marine forearc extension in the Hikurangi margin: new insights from high-resolution 3-D seismic data. Tectonics 37 (5), 1472-1491.

Chadwick, W.W., Merle, S.G., Buck, N.J., Lavelle, J.W., Resing, J.A., Ferrini, V., 2014 Imaging of $\mathrm{CO}_{2}$ bubble plumes above an erupting submarine volcano, NW Rota-1, Mariana Arc. Geochem. Geophys. Geosyst. 15 (11), 4325-4342.

Clark, J.F., Washburn, L., Hornafius, J.S., Luyendyk, B.P., 2000. Dissolved hydrocarbon flux from natural marine seeps to the southern California Bight. J. Geophys. Res. Oceans 105 (C5), 11509-11522.

Collot, J.-Y., Delteil, J., Lewis, K.B., Davy, B., Lamarche, G., Audru, J.-C., Barnes, P., Chanier, F., Chaumillon, E., Lallemand, S., 1996. From oblique subduction to intracontinental transpression: structures of the southern Kermadec-Hikurangi margin from multibeam bathymetry, side-scan sonar and seismic reflection. Mar. Geophys. Res. 18 (2-4), 357-381.

Colwell, F., Boyd, S., Delwiche, M., Reed, D., Phelps, T., Newby, D., 2008. Estimates of biogenic methane production rates in deep marine sediments at Hydrate Ridge, Cascadia Margin. Appl. Environ. Microbiol. 74 (11), 3444-3452.

Crutchley, G.J., Pecher, I.A., Gorman, A.R., Henrys, S.A., Greinert, J., 2010. Seismic imaging of gas conduits beneath seafloor seep sites in a shallow marine gas hydrate province, Hikurangi Margin, New Zealand. Mar. Geol. 272 (1), 114-126.

Datta, R., Napier, D., Newitt, D., 1950. The properties and behaviour of gas bubbles formed at circular orifices. In: Proceedings Chemistry \& Industry. Soc Chemical Industry, 14 Belgrave Square, London Sw1x 8PS, England, pp. 168.

Davey, F., Hampton, M., Childs, J., Fisher, M., Lewis, K., Pettinga, J., 1986. Structure of a growing accretionary prism, Hikurangi margin, New Zealand. Geology 14 (8), 663-666.

DelSontro, T., McGinnis, D.F., Wehrli, B., Ostrovsky, I., 2015. Size does matter: Importance of large bubbles and small-scale hot spots for methane transport. Environ. Sci. Technol. 49 (3), 1268-1276.

Din, F., 1961. Thermodynamic Functions of Gases: Methane, Nitrogen, Ethane. Butterworths Scientific Publications.

Dupré, S., Scalabrin, C., Grall, C., Augustin, J.M., Henry, P., Şengör, A.C., Görür, N., Çağatay, M.N., Géli, L., 2015. Tectonic and sedimentary controls on widespread gas emissions in the Sea of Marmara: results from systematic, shipborne multibeam echo sounder water column imaging. J. Geophys. Res. Solid Earth 120 (5), 2891-2912.

Field, B.D., Uruski, C., 1997. Cretaceous-Cenozoic Geology and Petroleum Systems of the East Coast Region, New Zealand. Institute of Geological \& Nuclear Sciences.

Gibson, R., Atkinson, R., Gordon, J., 2005. Ecology of Cold Seep Sediments: Interactions of Fauna With Flow, Chemistry and Microbes: Oceanography and Marine Biology: An Annual Review. vol. 43. pp. 1-46.

Greinert, J., Nützel, B., 2004. Hydroacoustic experiments to establish a method for the determination of methane bubble fluxes at cold seeps. Geo-Mar. Lett. 24 (2), 75-85.

Greinert, J., Lewis, K., Bialas, J., Pecher, I.A., Rowden, A., Bowden, D., De Batist, M., Linke, P., 2010. Methane seepage along the Hikurangi Margin, New Zealand: overview of studies in 2006 and 2007 and new evidence from visual, bathymetric and hydroacoustic investigations. Mar. Geol. 272 (1), 6-25.

Guinasso, N.L., Schink, D.R., 1973. A Simple Physicochemical Acoustic Model of Methane Bubbles Rising in the Sea. Texas A \& M University, College of Geosciences.

Heeschen, K.U., Tréhu, A.M., Collier, R.W., Suess, E., Rehder, G., 2003. Distribution and height of methane bubble plumes on the Cascadia Margin characterized by acoustic imaging. Geophys. Res. Lett. 30 (12).

Judd, A., Davies, G., Wilson, J., Holmes, R., Baron, G., Bryden, I., 1997. Contributions to atmospheric methane by natural seepages on the UK continental shelf. Mar. Geol. 137 (1-2), 165-189.

Koch, S., Berndt, C., Bialas, J., Haeckel, M., Crutchley, G., Papenberg, C., Klaeschen, D., Greinert, J., 2015. Gas-controlled seafloor doming. Geology 43 (7), 571-574.

Koch, S., Schroeder, H., Haeckel, M., Berndt, C., Bialas, J., Papenberg, C., Klaeschen, D., Plaza-Faverola, A., 2016. Gas migration through Opouawe Bank at the Hikurangi margin offshore New Zealand. Geo-Mar. Lett. 36 (3), 187-196.

Kossel, E., Bigalke, N.K., Pinero, E., Haeckel, M., 2013. The SUGAR Toolbox: A Library of Numerical Algorithms and Data for Modelling of Gas Hydrate Systems and Marine Environments. vol. 8 PANGEA, Bremenhaven. https://doi.org/10.3289/GEOMAR_ REP NS 8 2013. 160 p. GEOMAR Report (N. Ser.). (PANGAEA).

Krabbenhöft, A., Netzeband, G., Bialas, J., Papenberg, C., 2010. Episodic methane concentrations at seep sites on the upper slope Opouawe Bank, southern Hikurangi Margin, New Zealand. Mar. Geol. 272 (1), 71-78.
Ladroit, Y., Lamarche, G., Pallentin, A., 2018. Seafloor multibeam backscatter calibration experiment: comparing $45^{\circ}$-tilted $38-\mathrm{kHz}$ split-beam echosounder and $30-\mathrm{kHz}$ multibeam data. Mar. Geophys. Res. 39 (1-2), 41-53.

Leifer, I., Culling, D., 2010. Formation of seep bubble plumes in the Coal Oil Point seep field. Geo-Mar. Lett. 30 (3-4), 339-353.

Leifer, I., Patro, R.K., 2002. The bubble mechanism for methane transport from the shallow sea bed to the surface: a review and sensitivity study. Cont. Shelf Res. 22 (16), 2409-2428.

Leifer, I., de Leeuw, G., Cohen, L., 2000a. Secondary bubble production from breaking waves: the bubble burst mechanism. Geophys. Res. Lett. 27 (24), 4077-4080.

Leifer, I., Patro, R.K., Bowyer, P., 2000b. A study on the temperature variation of rise velocity for large clean bubbles. J. Atmos. Ocean. Technol. 17 (10), 1392-1402.

Lewis, K.B., Marshall, B.A., 1996. Seep faunas and other indicators of methane-rich dewatering on New Zealand convergent margins. N. Z. J. Geol. Geophys. 39 (2), $181-200$.

Lewis, K., Pettinga, J., 1993. The Emerging, Imbricate Frontal Wedge of the Hikurangi Margin: Sedimentary Basins of the World. vol. 2. pp. 225-250.

Luo, M., Dale, A.W., Haffert, L., Haeckel, M., Koch, S., Crutchley, G., De Stigter, H., Chen, D., Greinert, J., 2016. A quantitative assessment of methane cycling in Hikurangi Margin sediments (New Zealand) using geophysical imaging and biogeochemical modeling. Geochem. Geophys. Geosyst. 17 (12), 4817-4835.

Mazzini, A., Ivanov, M., Parnell, J., Stadnitskaia, A., Cronin, B., Poludetkina, E., Mazurenko, L., van Weering, T., 2004. Methane-related authigenic carbonates from the Black Sea: geochemical characterisation and relation to seeping fluids. Mar. Geol. 212 (1), 153-181.

McGovern, 2012. Video-Based Quantification of Gas Bubble Fluxes From the Seafloor Offshore Western Svalbard. MSc in Marine Geosciences. University of Bremen (44 p).

Mendelson, H.D., 1967. The prediction of bubble terminal velocities from wave theory. AICHE J. 13 (2), 250-253.

Miyake, Y., Koizumi, M., 1948. The measurement of the viscosity coefficient of sea water. J. Mar. Res. 7 (2), 63 v.

Mountjoy, J.J., Barnes, P.M., 2011. Active upper-plate thrust faulting in regions of low plate-interface coupling, repeated slow slip events, and coastal uplift: example from the Hikurangi Margin, New Zealand. Geochem. Geophys. Geosyst. 12, Q01005. https://doi.org/10.1029/2010GC003326.

Muyakshin, S., Sauter, E., 2010. The hydroacoustic method for the quantification of the gas flux from a submersed bubble plume. Oceanology 50 (6), 995-1001.

Naudts, L., Greinert, J., Artemov, Y., Staelens, P., Poort, J., Van Rensbergen, P., De Batist, M., 2006. Geological and morphological setting of 2778 methane seeps in the Dnepr paleo-delta, northwestern Black Sea. Mar. Geol. 227 (3), 177-199.

Naudts, L., Greinert, J., Poort, J., Belza, J., Vangampelaere, E., Boone, D., Linke, P., Henriet, J.-P., De Batist, M., 2010. Active venting sites on the gas-hydrate-bearing Hikurangi Margin, off New Zealand: diffusive-versus bubble-released methane. Mar. Geol. 272 (1), 233-250.

Netzeband, G., Krabbenhöft, A., Zillmer, M., Petersen, C.J., Papenberg, C., Bialas, J., 2010. The structures beneath submarine methane seeps: seismic evidence from Opouawe Bank, Hikurangi Margin, New Zealand. Mar. Geol. 272 (1), 59-70.

Ostrovsky, I., McGinnis, D.F., Lapidus, L., Eckert, W., 2008. Quantifying gas ebullition with echosounder: the role of methane transport by bubbles in a medium-sized lake. Limnol. Oceanogr. Methods 6 (2), 105-118.

Pecher, I., Villinger, H., Kaul, N., Crutchley, G., Mountjoy, J., Huhn, K., Kukowski, N., Henrys, S., Rose, P., Coffin, R., 2017. A fluid pulse on the Hikurangi subduction margin-evidence from a heat flux transect across the upper limit of gas hydrate stability. Geophys. Res. Lett. 44 (24), 12-385.

Plaza-Faverola, A., Pecher, I., Crutchley, G., Barnes, P.M., Bünz, S., Golding, T., Klaeschen, D., Papenberg, C., Bialas, J., 2014. Submarine gas seepage in a mixed contractional and shear deformation regime: cases from the Hikurangi oblique-subduction margin. Geochem. Geophys. Geosyst. 15 (2), 416-433.

Pohlman, J.W., Greinert, J., Ruppel, C., Silyakova, A., Vielstädte, L., Casso, M., Mienert, J., Bünz, S., 2017. Enhanced $\mathrm{CO}_{2}$ uptake at a shallow Arctic Ocean seep field overwhelms the positive warming potential of emitted methane. Proc. Natl. Acad. Sci. 114 (21), 5355-5360.

Prasad, R., Kennedy, L.A., Ruckenstein, E., 1984. Catalytic combustion. Catal. Rev. Sci. Eng. 26 (1), 1-58.

Rehder, G., Leifer, I., Brewer, P.G., Friederich, G., Peltzer, E.T., 2009. Controls on me thane bubble dissolution inside and outside the hydrate stability field from open ocean field experiments and numerical modeling. Mar. Chem. 114 (1), 19-30.

Riedel, M., Crutchley, G., Koch, S., Berndt, C., Bialas, J., Eisenberg-Klein, G., Prüßmann, J., Papenberg, C., Klaeschen, D., 2018. Elongate fluid flow structures: stress control on gas migration at Opouawe Bank, New Zealand. Mar. Pet. Geol. 92, 913-931.

Ritger, S., Carson, B., Suess, E., 1987. Methane-derived authigenic carbonates formed by subduction-induced pore-water expulsion along the Oregon/Washington margin. Geol. Soc. Am. Bull. 98 (2), 147-156.

Römer, M., Sahling, H., Pape, T., Bohrmann, G., Spieß, V., 2012. Quantification of gas bubble emissions from submarine hydrocarbon seeps at the Makran continental margin (offshore Pakistan). J. Geophys. Res. Oceans 117 (C10).

Römer, M., Riedel, M., Scherwath, M., Heesemann, M., Spence, G.D., 2016. Tidally controlled gas bubble emissions: a comprehensive study using long-term monitoring data from the NEPTUNE cabled observatory offshore Vancouver Island. Geochem. Geophys. Geosyst. 17 (9), 3797-3814.

Römer, M., Wenau, S., Mau, S., Veloso, M., Greinert, J., Schlüter, M., Bohrmann, G., 2017. Assessing marine gas emission activity and contribution to the atmospheric methane inventory: a multidisciplinary approach from the Dutch Dogger Bank seep area (North Sea). Geochem. Geophys. Geosyst. 18 (7), 2617-2633.

Rueff, R.M., Dendy Sloan, E., Yesavage, V.F., 1988. Heat capacity and heat of dissociation 
of methane hydrates. AICHE J. 34 (9), 1468-1476.

Schneider von Deimling, J., Rehder, G., Greinert, J., McGinnnis, D., Boetius, A., Linke, P. 2011. Quantification of seep-related methane gas emissions at Tommeliten, North Sea. Cont. Shelf Res. 31 (7-8), 867-878.

Shakhova, N., Semiletov, I., Leifer, I., Sergienko, V., Salyuk, A., Kosmach, D., Chernykh, D., Stubbs, C., Nicolsky, D., Tumskoy, V., 2014. Ebullition and storm-induced methane release from the East Siberian Arctic Shelf. Nat. Geosci. 7 (1), 64-70.

Sibuet, M., Olu, K., 1998. Biogeography, biodiversity and fluid dependence of deep-sea cold-seep communities at active and passive margins. Deep-Sea Res. II Top. Stud. Oceanogr. 45 (1-3), 517-567.

Tang, Q.-h., Zhou, X.-h., Liu, Z.-c., DU, De-wen, 2005. Processing multibeam backscatter data. Mar. Geod. 28 (3), 251-258.

Torres, M., McManus, J., Hammond, D., De Angelis, M., Heeschen, K., Colbert, S., Tryon, M., Brown, K., Suess, E., 2002. Fluid and chemical fluxes in and out of sediments hosting methane hydrate deposits on Hydrate Ridge, OR, I: hydrological provinces. Earth Planet. Sci. Lett. 201 (3), 525-540.

Townend, J., 1997. Subducting a Sponge; Minimum Estimates of the Fluid Budget of the Hikurangi Margin Accretionary Prism. vol. 112. Geol. Soc. NZ Newsl, pp. 14-16.

Urban, P., Köser, K., Greinert, J., 2017. Processing of multibeam water column image data for automated bubble/seep detection and repeated mapping. Limnol. Oceanogr. Methods 15 (1), 1-21.

Valentine, D.L., Blanton, D.C., Reeburgh, W.S., Kastner, M., 2001. Water column methane oxidation adjacent to an area of active hydrate dissociation, Eel River Basin. Geochim. Cosmochim. Acta 65 (16), 2633-2640.

Veloso, M., Greinert, J., Mienert, J., De Batist, M., 2015. A new methodology for quantifying bubble flow rates in deep water using splitbeam echosounders: examples from the Arctic offshore NW-Svalbard. Limnol. Oceanogr. Methods 13 (6), 267-287.

Wallace, L.M., Webb, S.C., Ito, Y., Mochizuki, K., Hino, R., Henrys, S., Schwartz, S.Y. Sheehan, A.F., 2016. Slow slip near the trench at the Hikurangi subduction zone, New Zealand. Science 352 (6286), 701-704.

Weber, T.C., Mayer, L., Jerram, K., Beaudoin, J., Rzhanov, Y., Lovalvo, D., 2014. Acoustic estimates of methane gas flux from the seabed in a $6000 \mathrm{~km}^{2}$ region in the Northern Gulf of Mexico. Geochem. Geophys. Geosyst. 15 (5), 1911-1925.

Woolf, D.K., 1993. Bubbles and the air-sea transfer velocity of gases. Atmosphere-Ocean 31 (4), 517-540

Woolf, D.K., Thorpe, S., 1991. Bubbles and the air-sea exchange of gases in near-saturation conditions. J. Mar. Res. 49 (3), 435-466. 